\title{
AGAMBEN, DELFINI E A INDETERMINAÇÃO DE VIVIDO E POETADO
}

\author{
Federico Fastelli \\ Università di Firenze
}

\author{
Tradução de \\ Bárbara Cristina Mafra dos Santos** \\ Elena Santi** \\ Universidade Federal de Santa Catarina
}

\begin{abstract}
Resumo: O ensaio discute a interpretação original de Giorgio Agamben sobre a obra do escritor italiano Antonio Delfini. Em particular, o ensaio analisa a centralidade da reflexão poética de Delfini no sistema estético agambeniano: a intransigência antimoderna de Delfini é, de fato, ligada por Agamben a uma reflexão geral sobre a natureza da palavra poética e relativa às mutações históricas da complexa relação entre obra e biografia na cultura literária ocidental. Nesse sentido, o ensaio reflete sobre o paralelo identificado por Agamben entre o significado profundo do conto Il ricordo della Basca e a ideia de uma "pura língua" prébabelica falada por Benjamin em seu famoso trabalho na Tarefa do tradutor e em muitas outras ocasiões. Serão examinados também outros textos do escritor de Môdena, principalmente da produção em versos, escolhidos na coletânea Poesie della fine del mondo, del prima e del dopo; mas a reflexão não deixará de lado também os diários e as cartas de Delfini, buscando oferecer um panorama amplo de sua produção.

Palavras-chave: Giorgio Agamben. Antonio Delfini. Língua e história.
\end{abstract}

Esta obra está licenciada sob uma Creative Commons - Atribuição 4.0

\footnotetext{
*É pesquisador de literatura comparada na Universidade de Florença. Seus estudos se concentraram principalmente na vanguarda europeia da segunda metade do século XX e nas relações entre literatura e artes visuais. Dedicou ensaios as obras de E. Sanguineti, A. Arbasino, N. Balestrini, G. Morselli, A. Robbe-Grillet, M. Butor, G. Testori, P. Bigongiari, L. Marcucci. Publicou a primeira monografia sobre a poesia de Elio Pagliarani (Dall'avanguardia all'eresia. L'opera poetica di Elio Pagliarani, Florença, 2011). Escreveu ensaios sobre a teoria da vanguarda, o teatro do Grupo 63, à retórica da Poesia Visual e Poesia Concreta, à serialidade televisiva. $\mathrm{O}$ interesse pelos acontecimentos internacionais da novela experimental é a base de sua segunda monografia, Il Nuovo Romanzo La narrativa d'avanguardia nella prima fase della postmodernità (1953-1973) (FLORENÇA, 2013). Junto com T. Spignoli, M. Corsi e M. C. Papini, editou o volume La poesia in immagine/L'immagine in poesia (UDINE, 2014). E-mail: federico.fastelli@unifi.it.

${ }^{* *}$ Licenciada em Letras e Literaturas Estrangeiras pela Universidade Federal de Santa Catarina. Atualmente é mestranda e bolsista CAPES do Programa de Pós-Graduação de Literatura da mesma universidade tendo como objeto de estudo os textos teatrais do autor italiano Dario Fo. Possui formação também como atriz, tendo parte da formação na Accademia di Teatro e Recità de Roma. Atua principalmente nas áreas de literatura italiana do século XX, literatura teatral e língua italiana. E-mail: barbaracmafra@gmail.com.

*** Possui Mestrado em Italianistica pela Università di Bologna (2014) e graduação em Lettere pela mesma instituição (2011). Tem experiência na área de Letras, com ênfase em Literatura Comparada e Poesia italiana do Século XX. É bolsista CAPES e atualmente integra o grupo de pesquisadores do Núcleo de Estudos Contemporâneos de Literatura Italiana (NECLIT). Também faz parte do grupo Literatura Italiana Traduzida no Brasil e suas tendências (UFSC-USP). E-mail: elena.santi1989@gmail.com.
}

Anu. Lit., Florianópolis, v. 22, n. 2, p. 12-24, 2017. ISSNe 2175-7917 
No paradigmático (AGAMBEN, 2008a, p. 11-34) e declaradamente provisório parterre literário, traçado pelas suas Categorias Italianas, Giorgio Agamben coloca Antonio Delfini em uma posição nada liminar. Um limiar extremo, se quisermos utilizar uma linguagem mais adequada ao assunto, ou um "espaço de exceção" da sua própria reflexão literária - retomando livremente os termos utilizados por Claudio Minca (MINCA, 2006, p. 387-340) - que, se bem observarmos, o escritor de Modena ocupa em extrema solidão. Assim, mesmo estendendo a discussão para toda a modernidade literária europeia, tal espaço não se lotaria de ulteriores presenças, com a valiosa exceção de Franz Kafka que, no entanto, como todos sabem, já é em si uma personalidade excepcional, e se encontra, por isso, em muitos dos lugares nevrálgicos da reflexão não apenas estética agambeniana. Em suma, se a condição de Delfini beira a unicidade, é porque esse, na ótica do filósofo, possui algumas qualidades deveras não usuais, capazes, de fato, de interceptar, em um dos seus focos, a própria reflexão basilar sobre a relação entre Língua e história (AGAMBEN, 2005). Parece curioso, à primeira vista, que esta importante tarefa seja, justamente, responsabilidade de um escritor que apesar do trabalho de alguns comentadores influentes - ainda hoje tenha dificuldades em confirmar sua presença no limitado cenário da literatura nacional canônica. Por outro lado, considerar o paradoxo simplesmente como aparente, isto é, resolver a questão por pura tautologia, uma vez que esse "estado exceção" poderia constituir, já em si, a razão para a marginalidade do escritor, não parece uma hipótese totalmente suficiente: não o é sobretudo pelo valor de Delfini, também considerando - como a experiência de Kafka demonstra sem equívocos - que a inclusão de um escritor naquilo que Romano Luperini definiria como o $a$ parte subjecti do cânone (LUPERINI apud OLIVIERI, 2001, p. 154-173), ultrapassa muito frequentemente os excessos de determinadas posições, certamente incomuns ou extremas ou solitárias, pelo menos na modernidade pós baudelairiana. Nem, no fundo, a notória profissão de automarginalização de Delfini - já, amplamente historicizada - pode conduzir, mais uma vez, a uma obrigação infrutífera de uma circulação memorial tão avessa. Mas, o paralelo, já feito entre a marginalidade de Delfini e a sua colocação na categorização estética de Agamben, não é suficiente para entender a questão nem mesmo em relação ao pensamento isolado deste último. Por trás da "obstinada distração da crítica em relação ao escritor de Modena" (GUICCIARDI apud POLLICELLI, 1990, p. 195, tradução nossa), para dizê-lo com Luigi Guicciardi, deve-se supor, antes, a insurgência de atritos bem mais profundos e estruturais, como se a poética delfiniana brigasse, literalmente, com certa ideia, por assim dizer, dominante da literatura - e justamente nesta chave Andrea Cortellessa falou com razão 
da "necessidade" de Delfini (CORTELLESSA, 2014, tradução nossa). Então, até mesmo a leitura de Agamben, se estou compreendendo bem, organiza-se precisamente a partir deste ponto, e mais, nisso encontra o núcleo de toda capacidade daquela mesma obra "de ser desenvolvida" (AGAMBEN, 2008a, p. 7-8, tradução nossa), ou seja, com o termo utilizado por Feuerbach e retomado pelo próprio Agamben, em Signatura Rerum, a sua Entwicklungsfähigkeit.

Seguindo passo a passo, encontramos, entretanto, o limes do que aqui se trata. Escreve Agamben:

em Delfini, como talvez em nenhum outro escritor do Novecentos, a indeterminação de vivido e poetado é tão absoluta que a vida é verdadeiramente apenas o que se gera na palavra. Nesse sentido, ele é o herdeiro mais autêntico da tradição trovadoresca e estilonovista e toda a sua obra pode ser vista como uma singular promissória que retorna depois de sete séculos para a cultura que produziu as biografias provençais. (AGAMBEN, 2014, p. 108)

A singularidade de Delfini, no cenário literário do século XX, depende, como se entende, da dialética entre "vivido" e "poetado": a peculiaridade do escritor se encontra na “indeterminação absoluta” dessa relação, ou seja, explica Agamben, no fato que, para Delfini, "vida é verdadeiramente apenas o que se gera na palavra" (AGAMBEN, 2014, p. 108). Devemos ter muito cuidado com essa definição: em primeiro lugar essa implica o transbordarse do moderno mal entendido em relação à natureza da palavra poética, já que, como para os trovadores provençais, também no caso de Delfini não se trata de expressar, em palavras, eventos psicológicos ou biográficos precedentemente vividos; para os primeiros, assim como para segundos, se trata, pelo contrário, da "tentativa de viver o topos em si, o evento de linguagem como fundamental experiência" (AGAMBEN, 2008b, p. 85, tradução nossa), biográfica e artística. Como Agamben explica em Il linguaggio e la morte, de fato, a virada, representada pela lírica provençal em relação à retórica antiga, tem a ver com o fato de que os trovadores concebem o homem "não já sempre na linguagem" (AGAMBEN, 2008b, p. 84, tradução nossa). A ars inveniendi do orador antigo recorria sim a uma topica, "uma técnica dos lugares (topoi) dos quais decorre e começa o discurso humano" (AGAMBEN, 2008b, p. 83, tradução nossa), mas a necessidade prática "de ter sempre a disposição os argumentos" (AGAMBEN, 2008b, p. 83, tradução nossa), tornou essa topica nada mais que mnemotécnica, uma técnica dos lugares da memória, em que, em essência, a linguagem resulta como algo "sempre já dado [...] alguma coisa que já teve sempre lugar" (AGAMBEN, 2008b, p. 84, tradução nossa). Ao contrário, para o trovador provençal, se tratou de voltar ao topos originário “do ter lugar em si da linguagem” (AGAMBEN, 2008b, p. 85, tradução nossa), não 
pelo viés da memória (no sentido mnemotécnico), mas, precisamente, como "experiência do advento da palavra poética" (AGAMBEN, 2008b, p. 85, tradução nossa), a qual, "no rastro do Appetitus agostiniano" (AGAMBEN, 2008b, p. 85, tradução nossa), os trovadores chamaram de Amors. A equivocada ideia moderna do amor trovadoresco como sentimento privado sempre levando em consideração o raciocínio agambeniano - dependeria, portanto, da inesperada concepção da relação entre vida e poesia, e, isto é, em detalhes, a partir de um malentendido sobre a função e o significado da razo na obra trovadoresca: as razos não representam, de acordo com Agamben, aquela vivência transformada em matéria que o poeta pode expressar em poesia, mas, precisamente, aquilo "que fundamenta a poesia e constitui aquilo que os poetas chamam o ditado (dictamen)" (AGAMBEN, 2014, p. 106). No capítulo de Ideia da Prosa intitulado Ideia do ditado, de fato, se lê:

quando a poesia era uma prática responsável, pressupunha-se que o poeta estaria sempre em condições de justificar o que havia escrito. Os provençais chamavam razo à exposição desta fonte escondida do canto, e Dante intimava o poeta, sob pena de cair em vergonha, a saber "abri-la em prosa". (AGAMBEN, 1999, p. 43)

É justamente nesse sentido, portanto, que devemos repensar a dialética entre a obra delfiniana e aquele sistema de "vida inventada", de "vida ficcional", de que numerosos críticos se ocuparam naquele tempo. Não somente a introdução do autor à edição de 1956 dos contos (DELFINI, 1956) aos quais Agamben retorna várias vezes, mas também a premissa e as notas a Poesie della fine del mondo (DELFINI, 2013), ou as cartas de amor (DELFINI, $1963)^{1}$, e, em certa medida, (à clareza do arbítrio antologizante de quem organizou sua edição póstuma) os diários (DELFINI, 1982) do escritor devem ser lidos como razos e colocados em relação, então, com a obra em si, no sentido de uma recíproca implicação, ao invés de um movimento univocamente direcionado entre os dois polos do vivido e do poetado. É claro, de fato, que a tentativa de "experimentar o evento de linguagem como amor" (AGAMBEN, 2008 b, p. 86, tradução nossa) dos trovadores provençais colocava em dialética o vivido e o poetado: não, porém, no sentido moderno de por em palavras os eventos biográficos, nem - e nos encontramos no ponto mais relevante da questão - no sentido diametralmente oposto, de modo que seria imediatamente e simplesmente o poetado a fornecer uma justificativa nobilitante aos eventos de uma vivência de outra maneira indefensável, falimentar. Para Agamben, a obra de Delfini, neste sentido, não só visa, como escreve Alfredo Giuliani,

\footnotetext{
${ }^{1}$ Veja-se o que escreve Agamben em Categorias Italianas, "pouco antes de partir para sua última estada em Roma, quando entrega sua carta de amor a Ugo e Michin Guanda, confuso por ter em suas mãos um "documento de amor" tão íntimo, Delfini se apressa em especificar com sobriedade de que "se tratava, no fim das contas, de uma oferta editorial"'" (AGAMBEN, 2014, p. 108-109).
}

Anu. Lit., Florianópolis, v. 22, n. 2, p. 12-24, 2017. ISSNe 2175-7917 
“'inventar' a vida e defender-se da realidade; experimentar a vida; vivê-la sem esquemas literários, para depois reencontrá-la na distância/proximidade da lembrança, porque somente a lembrança flutua na dúplice dimensão do vivido e do inventado" (GIULIANI apud POLLICELLI, 1990, p. 82, tradução nossa), se bem que, como veremos, é, em todo caso, na marca da lembrança que, da obra, irá se gerar catastroficamente um espaço de autonomia real do vivido. Nem a vida ficcional reproposta pelas razos é declinável como uma imediata projeção $^{2}$ de um desejo oculto, ou pior, expresso em via figurada ou alegórica na obra (também porque o estatuto da realidade que se revela nessas "histórias das histórias", por assim dizer, resulta muito pouco adequado a uma função de dissolução ou de desenrolamento das reticências biográficas eventualmente presentes nas obras) (CALABRESE, 2007, p. 15) ${ }^{3}$. Trata-se, contudo, de compreender a ligação entre vivido e poetado no interno daquilo que Agamben chama "viver a razo" (AGAMBEN, 2014, p. 107), e de compreendê-lo, se intui, por entre toda a própria extrema indeterminação.

Se, como tentamos expor, a razo "não é, desse modo, nem um evento biográfico nem um evento linguístico, mas, por assim dizer, uma zona de indiferença, entre vivido e poetado, um "viver a palavra" enquanto inexaurível experiência amorosa" (AGAMBEN, 2014, p. 106), "viver a razo" significará, propriamente, testemunhar a "autenticidade teológica da escritura" (AGAMBEN, 2014, p. 109) através, precisamente, do conto ficcional das próprias "falências biográficas" (AGAMBEN, 2014, p. 109), que é expressão - logo, já no começo, destinada ao fracasso - de um amor "fantasmático", de estilo medieval, do qual Agamben trata amplamente, como se sabe, em Infância e História:

a descoberta medieval do amor por obra dos poetas provençais e estilnovistas é, deste ponto de vista, a descoberta de que o amor tem como objeto não diretamente a coisa sensível, mas o fantasma; é, portanto, simplesmente a descoberta do caráter fantasmático do amor. Mas, dada a natureza medial da fantasia, isso significa que o fantasma é, também, o sujeito e não simplesmente o objeto do eros. Na medida em que, de fato, o amor tem o seu lugar único na fantasia, o desejo não encontra nunca diante de si o objeto na sua corporeidade [...], mas uma imagem [...], uma $<<$ nova pessoa $>>$ que é, literalmente, feita de desejo [...] na qual se abolem os confins entre

\footnotetext{
${ }^{2}$ Veja-se, nesse sentido, AMORUSO, V. La vita inventata: sulla narrativa di Delfini: "assim como Delfini a apresenta [...] a vida inventada não é aquela vivida nem aquela possível em um tempo real, não é nem o passado nem o futuro mas o projeto e, isto é, o desejo daquela, uma contemplação realmente leopardiana: como tal, contudo, mais que um objeto (uma coisa ou uma pessoa), se tem como centro, e, então, uma referência contínua, sempre em vão e sempre frustrada, à própria iteração, é, com uma palavra, desejo do desejo, espera do esperar, um movimento que contradiz seu mesmo impulso, porque não é teso para frente, em direção do fora, mas para trás e para dentro, nas vísceras de um tempo fora do tempo, que se convolve continuamente sobre ele mesmo, e, por tanto, em forma e sequência, realiza uma forma de imobilidade no movimento, ou melhor, ainda uma paradoxal, porque ao mesmo tempo inacabada e esférica, circularidade. (AMORUSO, p. 177, tradução nossa).

${ }^{3}$ Nesse sentido Stefano Calabrese falou de "reality show": "a definição atual de reality show - a realidade estetizada e vivida na perspectiva de um expectador, então uma realidade ficcional - é a mais idônea para identificar o perfil antropológico de Delfini as a young man".
}

Anu. Lit., Florianópolis, v. 22, n. 2, p. 12-24, 2017. ISSNe 2175-7917 
subjetivo e objetivo, corpóreo e incorpóreo, o desejo e o seu objeto. (AGAMBEN, 2005a, p. 35)

Esse amor, entende-se, exclui radicalmente cada sobrevivência de psicologismo pelo fato literário, todo tipo de descoberta do sentimento enquanto estado emotivo ou caráter da consciência, e se configura precisamente como nada mais que "intelecto de amor", saber, em suma, em que "verdade e beleza se comunicam" (AGAMBEN, 2015, p.57-58, tradução nossa $)^{4}$. Trata-se da própria experiência da linguagem, se quisermos dizer de outra forma, como incindível unidade, indeterminável, justamente, de vivido e poetado. Antonio Delfini, nesse sentido, é um poeta profundamente antimoderno: é ele, talvez, o único escritor do século XX a enfrentar explicitamente a questão do estatuto do vivido em relação à própria origem literária, no sentido, se entenda, da defesa pugnaz e impossível da autenticidade da escritura que, esse vivido, se encarrega de contar por inteiro, e, por outro lado, também de uma marcada superação - que Delfini compartilha mais uma vez com Kafka - de toda pretensão de justificar o real dado biográfico tornando-o autêntico por meio da escrita ${ }^{5}$. Somando esses dois aspectos, se deveria finalmente esclarecer, não somente a posição limite que Delfini ocupa, mas, bem mais profundamente, a sua substancial inadmissibilidade no âmbito do cânone moderno.

Para iluminar ainda mais este ponto, no entanto, devemos reler, sob outra ótica, a descontinuidade na poética delfiniana, constituída pela republicação de seus contos em 1956:

Delfini, acrescentando, em 1956, uma introdução à segunda edição de seus contos,
escreveu para Il ricordo della Basca (Recordação da Basca), a mais longa razo que
um poeta jamais imaginou para uma obra sua. Mas, como era geralmente hábito
entre os poetas de amor, a razo pode aqui também enganar o leitor. De fato, ela
sugere imediatamente um encaminhamento no sentido da biografia do autor,
biografia, naturalmente, inventada a partir da obra, mas que se arrisca a ser tomada
por verdadeira pelo leitor. A Basca, transparente senhal da língua e do "ditado" da
sua poesia, torna-se assim Isabel de Aranzadi, uma rapariga conhecida durante um 4 “É esse saber, em que verdade e beleza se comunicam, que, no ápice da filosofia grega, Platão tinha fixado na
figura demoníaca de Eros; e é ainda esse saber que, no limiar da idade moderna, tinha aparecido aos poetas do
século XII como "intelecto de amor" na figura beatificante de uma Mulher (Beatriz) em que, finalmente, a
ciência goza e o prazer sabe. O mitologema de Eros é necessariamente inscrito no destino da filosofia ocidental,
já que, para além da desagregação metafísica do significante e do significado, da aparência e do ser, da divinação
e da ciência, isso faz sinal para uma salvação integral dos fenômenos. Saber de amor, filosofia, significa: a
beleza deve salvar a verdade e a verdade deve salvar a beleza. Nessa dúplice salvação se cumpre o
conhecimento." - Tradução nossa, pois não tivemos acesso a obra.
5 “A "escritura psicológica no espelho" que, segundo uma genial anotação de Kafka no penúltimo dos seus
cadernos, dá a impressão de que os homens estejam incessantemente ocupados em consolidar a própria vida com
escrituras e justificações a posteriori, é aqui retificada com um gesto decidido de mostrar, contra toda leitura
psicológica, que "na realidade o homem erige a sua vida sobre as próprias justificações”, uma vez que "ninguém
aqui cria nada mais do que a sua possibilidade de vida espiritual”. É sobre esses arquétipos que, em todo caso,
tanto Delfini quanto Kafka construíram suas vidas. Suas falências biográficas (ou, ao menos, o que nos aparece
como tal na escritura invertida da psicologia) deveriam testemunhar acerca da autenticidade teológica da
escritura (do seu colocar-se no arché), e não esta justificá-las." (AGAMBEN, 2002, p. 109).

Anu. Lit., Florianópolis, v. 22, n. 2, p. 12-24, 2017. ISSNe 2175-7917 
verão em Lerici, 20 anos antes. (AGAMBEN, 1999, p. 43)

Em Um enigma da Basca (AGAMBEN, 2014, p. 187-192), Agamben expõe plenamente a sua posição na relação entre o conto em questão e a razo que o introduz: "abrindo para prosa" o "trobar clus" (AGAMBEN, 2014, p. 187) do Ricordo, a introdução cujo título original deveria ter sido propriamente Ricordo del Ricordo - "por que a Basca? Quem é? O que quer dizer?” (AGAMBEN, 2014, p. 187). Então, explica Agamben, a Basca, como todo senhal feminino de ascendência trovadoresca estilnovista é, obviamente também "símbolo da língua da poesia" (AGAMBEN, 2014, p. 188). Lembrar-se-á, de fato, como aparece a Basca a Giacomo Disvetri, no conto:

tinha descido uma menina que imediatamente o tinha olhado sorrindo, enquanto se dirigia ao pai dizendo entonces e outras duas palavras incompreensíveis. "São espanhóis", tinha dito um menino da vila. E, então, Giacomo, não se sabe por que, começou a chorar e, virando as costas para todos, fugiu de casa. (DELFINI, 1992, p. 183 , tradução nossa)

E eis como, ao contrário, o conto se desenvolve na razo:

um senhor, com traços finos e de postura extremamente senhoril, muito humilde nas roupas, ainda que fossem elegantes, estava pensativo, mantendo-se um pouco afastado de seus filhos (um menino e uma menininha): eles estavam conversando em uma língua de tal pungente doçura, que o meu coração, ouvindo-os, pareceu que quisesse parar os próprios batimentos para deixar as coisas suspensas para sempre naquele momento. (DELFINI, 1956, p. 85, tradução nossa)

O "porquê", o "quem", e "o que significa" a Basca constituem interrogações insuperáveis da experiência artística delfiniana: a autenticidade da experiência linguística da poesia atestada por meio da razo está toda, se se olhar bem, no fato que a Basca, na verdade, é uma mulher que, também, é uma língua desconhecida, precisamente a língua basca; ou seja, reciprocamente, de uma língua que, também, é uma mulher amada e desconhecida. Ao que tudo indica, este transcende qualquer significado realmente biográfico, e, como dissemos, se configura como a mesma experiência da língua poética, ou, mais propriamente, como experiência através da língua poética do fantasma como um sujeito-objeto de amors. De fato, é à fantasia que é necessário olhar para compreender o status angelical - no sentido estilnovistico - da Basca, que se apresenta à lembrança do protagonista do conto, como os leitores de Delfini estão lembrados, assim como "imaginação pura e separada do corpo" (AGAMBEN, 2005a, p. 35):

Uma imagem nasceu para ele: algo como uma moça. Tinha sentido dentro de si o som de uma voz lenta e brilhante ao mesmo tempo, clara, serena, tornada emotiva por certas inflexões, impossíveis de descrever, como poderiam, eventualmente, ser o luar iluminado em um gramado em que um gato rola modulando sons de satisfação e 
Somente mais tarde, efetivamente, "da voz foram, gradualmente, formando-se as aparências" (DELFINI, 1956, p. 181, tradução nossa). E é também interessante notar, aliás, que o narrador fala explicitamente de "despertar", entendendo a reapropriação da faculdade da experiência (do amor, da linguagem) em oposição ao conhecimento, ao pensamento ("se deu conta de não pensar mais”. Delfini, 1992, p. 181, tradução nossa) e, a referência, se não nos enganamos, é precisamente à expropriação moderna do cotidiano como matéria-prima da experiência:

a Giacomo, o despertar veio de repente, como acontece na maior parte desses casos. Aconteceu este ano, uma noite que saia mais cedo que o habitual do escritório: foi um momento. Conscientizou-se de não pensar mais no banco, nos discursos feitos no café, nas obscenidades habituais que faziam rir com uma espécie de mecânica doente da boca, nos lugares clichês, nos preconceitos, nas coisas dos jornais, nos acontecimentos de toda a vida corrente, no ressoar dos grandes e pequenos motivos musicais, no cinema, etc. (DELFINI, 1992, 180-181, tradução nossa)

Que, então, é exatamente o que Agamben descreve no primeiro parágrafo de Infância e história: "o homem moderno volta para casa à noitinha extenuado por uma mixórdia de eventos - divertidos ou maçantes, banais ou insólitos, agradáveis ou atrozes -, entretanto nenhum deles se tornou experiência" (AGAMBEN, 2005a, p. 22). Em todo caso, voltando à questão da Basca como senhal trovadoresco e estilnovistico, a reflexão do filósofo centra-se na composição poética, aparentemente glossolálica, que aparece na conclusão do conto, e, que resulta, na realidade, escrita propriamente em basco (AGAMBEN, 2014, p. 147-148). A impressão glossolálica, de fato, suporta por inteiro a tarefa da poesia, ou seja, indica o seu status de experiência da palavra como impossibile ricordo de uma língua "na qual o espírito de imediato se confunde com a voz" (AGAMBEN, 2014, p. 188), de algo que, isto é - a basca - "é aquilo tão íntimo e presente ao ponto de não poder ser de modo algum lembrado" (AGAMBEN, 2014, p. 188). Em suma, é o próprio retornar da língua ao momento tópico do ter lugar da linguagem, aquilo que está aqui em questão, e equivale - no fundo - à firme consciência que a mesma linguagem não é sempre já dada; ou ainda, dito em outros termos, que o homem tem, precisamente, segundo a terminologia agambeniana, uma infância:

se não houvesse a experiência do homem, certamente a língua seria um $<<$ jogo $>>$, cuja verdade coincidiria com o seu uso correto segundo regras lógico-gramaticais. Mas, a partir do momento em que existe uma experiência, que existe uma infância do homem, cuja expropriação é o sujeito da linguagem, a linguagem coloca-se então como o lugar em que a experiência deve tornar-se verdade. (AGAMBEN, 2005a, p. 62)

Como se entende, a partir dessa última passagem, a relevância que Agamben atribui 
a Delfini, o extremo limiar no qual o convoca, a insistência com a qual mais uma vez retorna sobre os mesmos argumentos, dependem do fato que, com Il ricordo della Basca, antes, e com Le poesie della fine del mondo, depois, e, em geral, com uma atitude poética constantemente voltada para "mito de uma língua na qual o espírito se confunde - pelo menos na aparência - imediatamente com a voz" (AGAMBEN, 1999, p. 44), o escritor de Modena coloca em causa "o estatuto absolutamente primordial da linguagem" (AGAMBEN, 2014, p. 104), a "demora do logos na $\operatorname{archè"~(AGAMBEN,~2014,~p.~104)~ou~seja,~a~negatividade~}$ fundamental que, desde sempre, marca e contra distingue a obra poca, e da qual a Basca constitui o enigma, e, o derradeiro estandarte ${ }^{6}$. Bem, a Basca delfiniana representa exatamente "aquilo que permanece indizível e não dito em toda língua" (AGAMBEN, 2005b, p. 44, tradução nossa) e que, enfim, coincide "justamente [com] aquilo que essa entende e quer dizer: a pura língua, a palavra inexpressiva.” (AGAMBEN, 2005b, p. 44, tradução nossa). Essa língua, tão desconhecida, e, ao mesmo tempo, tão amada, alude, nos termos benvenistianos, retomados por Agamben em Infância e história, à pura ordem semiótica de toda língua, em contraposição à ordem semântica. ${ }^{7}$ Alude, na verdade, ao que é próprio do signo linguístico, antes que isso se torne discurso, ou, por outro viés, o que não pode ser transposto de uma língua a outra, por exemplo, na prática da tradução. ${ }^{8}$ É a língua antes da história, a língua pura da infância do homem, e, como tal, não deve ser compreendida, mas simplesmente reconhecida:

O semiótico (o signo) deve ser RECONHECIDO; o semântico (o discurso) deve ser
COMPREENDIDO. A diferença entre reconhecer e compreender remete a duas
faculdades distintas do espírito: a de perceber a identidade entre o anterior e o atual,
por um lado, e a de perceber o significado de uma enunciação nova, por outro.
(AGAMBEN, 2005a, p. 67)

"Por que a Basca?" "Quem é a Basca?", “O que quer dizer a Basca?" São, relembramos, perguntas impossíveis. Talvez seja, justamente nesse sentido, que a obra de Delfini é relembrada por Agamben também na conclusão da intervenção Lingua e storia. Categorie linguistiche e categorie storiche in Walter Benjamin, como corajoso (e raro)

\footnotetext{
${ }^{6}$ Agamben retomará essas questões também em A comunidade que vem (trad. de Cláudio Oliveira, Belo Horizonte: Autêntica, 2013), Meios sem fim: notas sobre a política (trad. de Davi Pessoa, Autêntica, Belo Horizonte: Autêntica, 2015) e O aberto: o homem o animal (trad. de Pedro Barbosa Mendes, São Paulo: Civilização Brasileira, 2017).

7 "O semiótico designa o modo de significação que è próprio do SIGNO linguístico e o constitui como unidade. [...] Com o semântico, entramos no modo específico da significação gerado pelo DISCURSO” (BENVENISTE apud AGAMBEN, 2005b, p. 67).

${ }^{8}$ Pode-se transpor o semantismo de uma língua ao de outra, "salva veritate": é a possibilidade da tradução; mas não se pode transpor o semiotismo de uma língua ao de outra: é a impossibilidade da tradução. Toca-se aqui a diferença entre semiótico e semântico. (BENVENISTE apud AGAMBEN, 2005b, p. 67)
} 
experimento de pensar - benjaminianamente, de fato - "uma comunidade e uma língua humana que não remetessem mais a algum fundamento indizível e não se destinassem mais a um legado infinito, e no qual as palavras não se distinguissem mais de qualquer outra prática humana" (AGAMBEN, 2005b, p. 54, tradução nossa). Em outras palavras, Il ricordo della Basca, pode ser lido, se você captura corretamente a sugestão, como a tentativa impossível, já minada em princípio, e, portanto, de inalcançável coragem, de ultrapassar a "condição decaída da linguagem, consagrada pela confusão babélica das línguas" (AGAMBEN, 2005b, p. 42, tradução nossa) - das línguas na história - das quais Benjamin fala na célebre intervenção sobre a Tarefa do Tradutor, e em diversas outras ocasiões, para alcançar (e/ou retornar), de fato, àquela "pura língua" (AGAMBEN, 2005b, p. 43, tradução nossa) da "humanidade redimida", ou seja, àquela "palavra que não quer mais dizer, que não se destina mais ao legado histórico de um significado" (AGAMBEN, 2005b, p. 43, tradução nossa).

No entanto, como já mencionado, a composição poética que fecha o conto delfiniano é somente em aparência uma mera glossolalia, o que explica, não só, o sentido profundo do título Ricordo della Basca, mas também a extraordinária consciência da operação estética de Delfini. Como aponta o próprio Agamben:

A narrativa intitula-se, no entanto, Ricordo della Basca, para significar que a escrita é a tentativa, desde logo votada ao fracasso, de aprender esta proximidade imemorial, este amor que se não pode mandar à distância (daí a "tragédia irremediável desta recordação"). De resto, o poema, de que a própria narrativa é a razo, não é, realmente, uma glossolalia, mas uma copla em puríssima língua basca, que, em tradução, termina com os seguintes versos: "Quando enfim chego ao poema, / já o sono te vai chegando; / como um sonho em tua noite / seja para ti o meu canto". (AGAMBEN, 1999, p. 44)

Que significa, portanto, em termos mais gerais, que:

a experiência da língua poética (ou seja, do amor) é inteiramente compreendida na cisão entre uma presença imemorial e um poder apenas lembrar. A língua da poesia não é, portanto, uma perfeita glossolalia, na qual a cisão se sutura, assim como nenhuma língua humana, em que pese a sua tensão em relação ao absoluto, jamais pode, ultrapassando a medição do sentido, resolver-se sem resíduos em um "falar em língua". (AGAMBEN, 2014, p. 189)

O fracasso dessa abordagem é, precisamente, a impossibilidade do ricordo da Basca: “o desaparecimento da Basca é eterno, pois ela eternamente falta na língua dos homens, na qual se afirma somente através da babélica discordância dos múltiplos idiomas" (AGAMBEN, 2014, p. 189). O fracasso da lembrança, que se encontra no centro do conto delfiniano, e a razo, que constitui a lembrança desse "fracasso da lembrança", ou seja, a dissolução do seu ditado - em prosa, de fato, segundo os termos agambenianos - certificam, 
então, uma divisão intrínseca à linguagem do homem entre a língua e o discurso e preparam, evidentemente, o extremo e doloroso ponto de chegada da carreira de Delfini às Poesie della fine del mondo. Se, de fato, o ditado poético que estrutura Il ricordo, rege-se pela força de fé, sobre o fantasmático amor pela Basca, e a linguagem se mantém, então, o lugar onde a experiência se faz verdade, ao contrário da biografia real - "em retrospecto, digo, que se tivesse, então, tido um journal eu não poderia ter tido o tempo de ver, nem a inspiração de criar aquelas verdadeiras histórias, vivendo-os, não haveria tempo de escrevê-las" (DELFINI, 1956, p. 11, tradução nossa) - as Poesie della fine del mondo, como Agabem salienta, indicam " essa laceração, que abandona a vida à sua "verdadeira má sorte"” e que "reverbera, entretanto, e de modo imediato, na própria poesia, tornada agora "má poesia" que, todavia, o poeta não pode não escrever [...] Ou seja, o poeta deve - e é esse, na catástrofe, o evento mais atroz - romper o próprio ditado" (AGAMBEN, 2014, p. 110). E, nesse último sentido, realmente, a leitura agambeniana parece acertar e penetrar profundamente o texto do escritor. Convence, em particular, que justamente de tal ruptura dependa a preliminar "inversão da figura feminina, a quem os poetas de amor entregavam a imagem mais íntegra do seu ditado" (AGAMBEN, 2014, p. 111), que organiza a inteira coletânea e, na qual, a crítica muitas vezes acreditou em poder espelhar brutalmente o reflexo de notórios dados biográficos. Releia-se a Premessa aos poemas:

O poeta lembra, é remorso, vê e entrevê "É tudo culpa daquela data história" declara. Em seguida, muda de ideia. O poeta não é mais um poeta: é um assassino, assassinado. Tem uma senhora que o observa "É ela a causa do fim do mundo: é uma mulher, que fez perecer tudo!" Aquela senhora que o está assistindo enquanto morre é o símbolo da fraude, da traição e do pecado. (DELFINI, 2013, p. 97, tradução nossa)

E veja-se a coerência da leitura agambeniana:

a senhora (a Basca, inscrita na tradição dos senhal estilnovistas e provençais, entre Beatriz, Giovanna, Miellz de Domna, Dezirada, Bon Vezi), que levava a cifra da unidade de poetado e vivido, da vida na língua, agora extraída à força da caneta e da palavra, inverte-se em vida nua, símbolo horrível e obscuro "da fraude, da traição, do pecado". (AGAMBEN, 2014, p. 111)

E releia-se, finalmente, a partir dessa perspectiva - e, então, pela inexorável condição deste poeta tornado assassino e, para sempre, "condenado a matar sua "senhora", isto é, a sua própria vida e a sua própria poesia, a sua vida-poesia" (AGAMBEN, 2014, p. 110) - textos como Non più una storia, la vita, o Fin tanto, ou ainda $A$ Cesena, L'unica via possibile è la morte, Sono stanco, somente para citar os mais relevantes, neste sentido. Pensa-se, por exemplo, em versos como: 
Para tirar os fantasmas de volta

um médico de Roma me ordenou os calmantes:

não mais será falado para ti de amor e de amantes

mas apenas dos advogados de merda e de moedas soantes.

(DELFINI, 2013, p. 124, tradução nossa)

Nos quais, explicitamente, Delfini coloca em jogo a destruição daquele conceito "fantasmático" de Amore que deu acesso a uma satisfação sempre medial e sempre concedida, e que não é outra coisa que a própria poesia, uma poesia vazia, que coloca em cena a linguagem enquanto experiência autêntica, originária e absolutamente infundada. Aquela poesia é a autêntica vida: a única na qual o amor sabe reunir em si o desejo - ligado à fantasia, insaciável e incomensurável (AGAMBEN, 2005a, p. 36) - e a necessidade - ligado à realidade corpórea, mensurável e teoricamente satisfazível (AGAMBEN, 2005a, p. 36). Mas quando o espaço da fantasia entra, implacavelmente, também para Delfini, na ordem do irreal - "para tirar os fantasmas de volta / um médico de Roma me ordenou os calmantes" (DELFINI, 2013, p. 124, tradução nossa) - lá se rompe, inexoravelmente, o encanto desta língua que precede o discurso e todo significado: o amor se parte agora em dois componentes e o desejo se torna insatisfazível. Aqui não há mais espaço para a má poesia: "não mais será falado para ti de amor e de amantes" (DELFINI, 2013, p. 124, tradução nossa), mas, somente, a vilania da real esfera biográfica, ou, para fechar em má-poesia, aquele mundo, "mas apenas de advogados de merda e de moedas soantes" (DELFINI, 2013, p. 124, tradução nossa).

\section{Referências}

AGAMBEN, Giorgio. Ideia do Ditado. In: . Ideia da Prosa. Trad. João Barrento. Lisboa: Edições Cotovia., 1999.

. Infância e história: destruição da experiência e origem da história. Trad. Henrique Burigo. Belo Horizonte: Editora UFMG, 2005a.

. La potenza del pensiero: saggi e conferenze. Vicenza: Neri Pozza, $2005 \mathrm{~b}$.

. Signatura Rerum: sul metodo. Turim: Bollati Boringhieri, 2008a.

$2008 b$

. Il linguaggio e la morte: un seminario sul luogo della negatività. Turim: Einaudi,

Categorias italianas: estudos de poética e literatura. Trad. Vinicius Nicastro Honesko. Florianópolis: Editora UFSC, 2014.

. Gusto. Macerata: Quodlibet, 2015.

CALABRESE, Stefano. Antonio Delfini Verofinto: una metalessi italiana. Udine: Forum, 2007. 
CORTELLESSA, Andrea. Antonio Delfini: l'attacchino metafisico. In: Alfabeta 2.

Disponível em: <www.alfabeta2.it/2014/02/16/antonio-delfini-lattacchino-metafisico $>$. Acesso em: 10/092017.

DELFINI, Antonio. Il ricordo della Basca. Dieci racconti e una storia. Pisa: Nistri-Lischi, 1956.

. Lettere d'amore e Ritorno in città. Parma: Guanda, 1963.

. Il ricordo della Basca. Milão: Garzanti, 1992.

. Poesie della fine del mondo, del prima e del dopo. Turim: Einaudi, 2013.

DELFINI, Antonio; GUINZBURG, Natália (Org.). Diari 1927-1961. Turim: Einaudi, 1982.

GIULIANI, Alfredo. Le "poesia della fine del mondo". In: POLLICELLI, C. et al. (Org.). Antonio Delfini: Testimonianze e saggi.. Modena: Mucchi, 1990.

GUICCIARDI, Luigi. Cinquant'anni di disagio: la critica e Delfini. In: POLLICELLI, Cinzia. et al. (Org.). Antonio Delfini: testimonianze e saggi.. Modena: Mucchi, 1990.

LUPERINI, Romano. La questione del canone, la scuola e lo studio del Novecento. In: OLIVIERI, Ugo. (Org.). Un canone per il terzo millennio. Testi e problemi per lo studio del Novecento tra teoria della letteratura, antropologia e storia. Milão: Mondadori, 2001.

MINCA, Claudio. Giorgio Agamben end the new biopolitical Nomos. In: Geografiska Annaler. Series B, Human Geography, V. 88, n. 4, 2006, p. 387.

\section{Agamben, Delfini and the indeterminacy of lived and behaved}

Abstract: The essay discusses the original interpretation of Giorgio Agamben regarding the work of Italian writer Antonio Delfini. In particular, the essay analyzes the central importance of Delfini's poetic reflection on Agamben's aesthetic system: indeed, Agamben connects the anti-modern intransigence of Delfini to a general consideration on the poetic word and to the historic mutation of complex relationship between work and biography in Western literary culture. In this way, the essay reflects on the parallel identified by Agamben between the deep meaning of the tale Il ricordo della Basca and the idea of a pre-babelic "pure language" mentioned by Benjamin in his famous work about The Task of the Translator and in many others occasions. Other Môdema text will be examined, mainly the verses production, wich were chosen in Poesie della fine del mondo, del prima and del dopo collection; but the reflection do not put aside the Delfini diaries and letters, seeking out to offer a broad outlook of his production.

Keywords: Giorgio Agamben, Antonio Delfini, Language and history

Recebido em: 27/10/2017

Aceito em: 09/11/2017

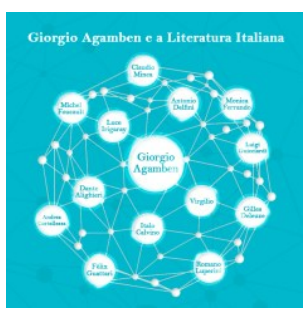

